\title{
Kernos
}

Revue internationale et pluridisciplinaire de religion grecque antique

18 | 2005

Varia

\section{Philippe BORGEAUD, Exercices de mythologie}

\section{Vinciane Pirenne-Delforge}

\section{(2) OpenEdition}

\section{Journals}

Édition électronique

URL : http://journals.openedition.org/kernos/1738

DOI : 10.4000/kernos. 1738

ISSN : 2034-7871

Éditeur

Centre international d'étude de la religion grecque antique

Édition imprimée

Date de publication : 1 janvier 2005

Pagination : 552-553

ISSN : 0776-3824

Référence électronique

Vinciane Pirenne-Delforge, «Philippe Borgeaud, Exercices de mythologie », Kernos [En ligne], 18 | 2005, mis en ligne le 24 mai 2011, consulté le 21 septembre 2020. URL : http://journals.openedition.org/ kernos/1738; DOI : https://doi.org/10.4000/kernos.1738 
«Sibylles fin de siècle », p. 273-284: la Sibylle sur la scène symboliste. L'ouvrage se termine par les sigles, p. 285 et la bibliographie générale, p. 287.

Emilio Suárez de la Torre (Universidad de Valladolid)

Ute Heidmann (éd.), Poétiques comparées des mythes. De l'Antiquité à la Modernité, Lausanne, Editions Payot, 2003. 1 vol. $14 \times 22,5$ cm, 256 p. ISBN : 2-601-03329-0.

Ce livre se veut un hommage adressé à Claude Calame quittant l'Université de Lausanne pour l'École Pratique des Hautes Études en Sciences Sociales à Paris. Lorsqu'on se rappelle les centres d'intérêts du destinataire, le livre s'en fait l'écho presque parfait. Il est résolument interdisciplinaire : philologie classique, anthropologie, linguistique, etc. s'y côtoient pour réaffirmer une des idées forces de l'œuvre de Calame : les récits que nous avons érigés en catégorie sous le terme de mythes ne sont accessibles qu'au travers de pratiques discursives particulières, et la méthode comparative, dont le but est la différenciation et non l'universalisation, illustre la multiplicité et la diversité de ce que l'on continue par commodité à appeler «les mythes » (pour la table des matières détaillée, voir Kernos 17 [2004], p. 351-352).

Ce livre est en quelque sorte, également, l'acte de naissance d'un Groupe de Recherche interdisciplinaire en Analyse comparée des discours né d'un dialogue continu et interdisciplinaire avec le travail de Claude Calame.

Vinciane Pirenne-Delforge (FNRS - Université de Liège)

Philippe Borgeaud, Exercices de mythologie, Genève, Labor et Fides, 2004. 1 vol. $15 \times 22 \mathrm{~cm}, 218$ p. ISBN : 2-8309-1141-5.

Ce livre est conçu, selon les termes de son auteur, comme « un répertoire ouvert, un recueil d'études à reprendre encore et toujours» (p. 7). Il ne s'agit donc pas d'un aboutissement, même s'il ponctue trente années d'« exercices » au cœur de la matière du mythe. Et Ph. Borgeaud assume encore et toujours son émerveillement devant ce matériau découvert à l'adolescence dans les ouvrages de Frazer et d'Eliade. Le préambule est limpide : il pose clairement les termes actuels de la question du mythe, qui est d'abord une histoire à raconter puis à comprendre. Le mythe est un récit qui tente de répondre à certaines questions et qui fait naître, par là même, un commentaire jamais achevé. L'interprétation est au cœur de chaque énonciation, mais la trame reste commune. Le répertoire narratif est une mémoire partagée qui s'ancre aussi dans les comportements rituels. Cette double manière traditionnelle de dire et de faire crée le style particulier à une communauté : la mémoire est donc culturelle et forge une identité. Les processus symboliques que sont le mythe et le rite forment les deux dimensions essentielles de cette tradition partagée qui, pour n'être pas l'objet d'un credo, n'en a pas moins un sens, fût-il fluide. S'appuyant sur le discours de Socrate les muthologèmata au bord de l'Ilissos (Platon, Phèdre, 229b-e), Ph. B. écrit que le mythe « relève d'une pratique sociale non problématique, une pratique du bonheur » (p. 30) Il s'agit d'une exploration ludique des limites de l'imaginaire psychologique et social.

Les sept réflexions qui suivent sont des articles plus ou moins retravaillés selon les cas, hormis le texte sur la musique de Pan qui était inédit. Le "mythe du labyrinthe » explore le motif en tant qu'espace imaginaire de l'initiation et livre un savant entrecroisement de la question des successions royales, entre Athènes et Crète. L'« enfance au 
miel » réunit Platon, Pindare, le chrétien Ambroise, mais aussi Zeus lui-même dans une commune relation au miel. Rhésos, un « cousin d'Orphée », est mis en regard de son prestigieux parent par la vertu des rapprochements et des écarts de leur biographie respective. Avec "Écho, désir, musique, les sentiers de Pan», Ph. B. retrouve le chemin de ses Recherches sur le dieu Pan (1979) et rejoint La Mère des dieux (1996) sur le thème de la musique. Quant à «la mort du Grand Pan », ce chapitre offre une remarquable leçon de méthode autour du curieux épisode rapporté par Plutarque (De la disparition des oracles, 17). S'interrogeant à la fois sur la portée du récit en contexte antique et sur les acrobaties interprétatives qui se sont succédé entre $\mathrm{XIX}^{\mathrm{e}}$ et $\mathrm{Xx}^{\mathrm{e}}$ siècle, $\mathrm{Ph}$. B. montre que le récit relève d'une propagande politique anti-impériale, revue ensuite dans une perspective apologétique chrétienne. En outre - et la leçon de méthode est là -, le comparatisme totalisant qui l'a intégré dans l'imagerie du « dieu qui meurt » ou dans le cadre folklorique de légendes nordiques montre avant tout la distance qui sépare les données et la succession de modes interprétatives. Ensuite, «la tête du Capitole » est une analyse fine et comparative des mécanismes idéologiques et historiques ayant mené à cette tradition: mise au jour d'une tête sur la colline tarpéienne, exploration du sens du prodige, tentative de détournement de l'oracle, reconnaissance de l'hégémonie à venir de Rome.

Le dernier volet de l'ouvrage n'entre pas tout à fait dans «l'exercice mythologique » du titre, même s'il a pleinement sa place dans ce regard rétrospectif sur un parcours, à la fois scientifique et personnel. Ph. B. fut l'élève de Mircea Eliade à Chicago dans les années septante et cette relation, même si elle fut moins déterminante que celle de Jean Rudhardt, a marqué le chercheur débutant en histoire des religions. Ce chapitre final, intitulé «Un mythe moderne : Mircea Eliade », est une mise au point rigoureuse et sensible de l'impact des « années noires » du savant roumain, quand il adhérait aux idées extrémistes de la Garde de Fer de Codreanu (1937-1944). Elle est rigoureuse car elle rend compte des dérives auxquelles un nationalisme exalté, soucieux de « respiritualiser l'individu», a mené Eliade, tout en continuant d'informer dans une certaine mesure sa vision méta-historique du sacré. Elle est sensible car certains excès du «révisionnisme» auquel a été soumise la carrière d'Eliade après sa mort ont manifestement blessé son ancien élève, qui a connu un autre homme "qu'il serait vain, absurde de vouloir à tout prix réduire au premier » (p. 202).

Ce livre remarquablement écrit montre la cohérence d'une démarche et l'application d'une méthode d'analyse des mythes qui rend compte de leurpoikilia en leur appliquant, sans exclusive, les acquis les plus intéressants des trois dernières décennies.

$$
\begin{aligned}
& \text { Vinciane Pirenne-Delforge } \\
& \text { (FNRS - Université de Liège) }
\end{aligned}
$$

Jean-Baptiste Bonnard, Le complexe de Zeus. Représentations de la paternité en Grèce ancienne, Paris, Publications de la Sorbonne, 2004. 1 vol. $16 \times 23,5$ cm, 254 p. ISBN : 2-85944-508-0.

Le discours grec sur la place du père dans le processus de la génération est au coeur de cet ouvrage tiré d'une thèse sur «La représentation du père de la cité. Contribution à l'étude de l'imaginaire dans la Grèce archaïque et classique », soutenue en 1998 à Paris I Panthéon-Sorbonne. J.-B. Bonnard y compare deux dossiers, l'un mythique, l'autre biologique, pour analyser les différentes manipulations discursives qui traduisent l'idéal d'un monde masculin déniant aux femmes le pouvoir de la reproduction. La démarche est originale et s'inscrit dans un courant comparatif qui 